\title{
MISI PENDIDIKAN NABI MUHAMMAD \\ (Kajian Tafsir Surat Al Anbiya (21): 107, Saba' 34:28)
}

\author{
Yahya Aziz ${ }^{1}$
}

\begin{abstract}
Abstrak
Sebagai rasul pemungkas, Nabi Muhammad di utus untuk seluruh umat manusia (khattaman linnası), tanpa batas waktu. Artinya sampai kapanpun ajaran beliau selalu relevan dan dibutuhkan. Skala jangkauannya bukan sebatas kapasitas mampu menjawab tantangan globalisme, tapi jauh melebihi itu, bahkan misinya rahmatal lil alamin (rahmat bagi seluruh alam semesta).

Rasulullah SAW memanifestasikan rohmatan lil alamin dengan 4 hal, yaitu : a) Pendidikan Tauhid; b) Pendidikan yang bernuansa duniawi ukhrowi; c) Peningkatan kualitas SDM dan d) Pendidikan suri tauladan (uswah hasanah). Tatkala ditanya, apakah sebenarnya hakekat agama? jawab Nabi "addinu husnul khuluq" agama adalah berbudi luhur dalam bermasyarakat, berkeluarga, berbisnis, berpolitik, berpendidikan dan sebagainya. Ibarat lingkaran raksasa, titik pusatnya kasih sayang (rahmat) dan pedomannya kitab suci Al-Qur'an.
\end{abstract}

Kata kunci : Rohmatan lil alamin, uswah hasanah, manifestasi.

Al-Qur'an adalah himpunan firman Allah yang bersifat mukjizat. Kandungan yang multi dimensional tidak hanya merupakan ajaran-ajaran agama yang berdimensi teologis ritualistik, seperti aqidah, ibadah dan akhlak, tetapi juga mengungkapkan pedoman dan arahan kehidupan sosial seperti ekonomi, politik, budaya, hubungan antar bangsa serta pendidikan, akan senantiasa eksis dan konsis dalam segala perkembangan situasi dan kondisi. Sebagai pedoman hidup manusia dalam menata kehidupan agar mencapai kebahagiaan dunia dan akhirat, ia akan selalu mampu menjawab segala macam problematika kehidupan yang dihadapi oleh umat manusia.

Seperti ayat-ayat tentang misi pendidikan Nabi Muhammad di dalam AlQur'an yang umumnya berisi konsep, prinsip pokok yang belum terjabar, perlu dijelaskan, dijabarkan dan dioperasionalisasikan agar mudah diaplikasikan dalam kehidupan.

\footnotetext{
${ }^{1}$ Dosen pada IAIN Sunan Ampel Surabaya.
} jsh Jurnal Sosial Humaniora, Vo. 2, No. 1, Juni 2009 


\section{Ayat-ayat tentang Misi Pendidikan Nabi Muhammad}

\section{Wamaa arsalnaaka illa rohmatan lil aalamiin}

"Dan tiadalah Kami mengutus kamu, melainkan untuk (menjadi) rahmat bagi semesta alam" (21: 107)

Wamaa arsalnaaka illa kaffatan linnaasi basyiron wanadzron walaakinna aksaron-naasi laa ya'lamuun.

"Dan kami tidak mengutus kamu, melainkan kepada umat manusia seluruhnya sebagai pembawa berita gembira dan sebagai peringatan, tetapi kebanyakan manusia tiada mengetahui" (34:28)

\section{Tafsir Mufrodat}

1. Wamaa : Dan tidak

2. Arsalnaaka : Kami mengutus kamu

3. Illa : melainkan

4. Rohmatan lil aalamiin: Rahmat bagi seluruh alam

5. Kaffatan : seluruh

6. Basyiron : Pembawa kabar gembira

7. Wanadzron : dan pemberi peringatan

8. Laa ya'lamuun : mereka tidak mengetahui (Tarjamah,1993).

\section{Penjelasan Ayat}

\section{Surat Al-Anbiya' (21):107}

Redaksi ayat di atas singkat, tetapi mengandung makna yang luas. Hanya dengan lima kata yang terdiri dari 25 huruf, ayat ini menyangkut 4 hal: a) Rasul/ utusan Allah dalam hal ini Muhammad, b) yang mengutus beliau Allah, c) yang diutus kepada mereka (al-alamin) serta d) risalah yang kesemuanya mengisyaratkan sifat-sifat rahmat bagi seluruh alam tidak terbatas pada manusia, waktu dan tempat. 
Dengan rahmat terpenuhilah hajat batin manusia untuk meraih ketenangan, ketenteraman, serta pengakuan atas wujud, hak, bakat dan fitrahnya, sehingga melahirkan sumber daya manusia yang berkualitas.(Shihab,2004).

Sedangkan menurut Hamka ketika menafsirkan ayat ini, bahwa setiap ajaran Nabi Muhammad adalah sistem yang membawa kebahagiaan seluruh umat manusia, risalah Muhammad datang ke dunia ini setelah sampai pada kedewasaan akal, ada 3 rahmat bagi seluruh rahmat manusia yaitu:

a. Rahmat kemerdekaan berfikir sehingga akal tidak takut kemajuan zaman.

b. Rahmat keseimbangan batin manusia yaitu keseimbangan jasmani dan rohani.

c. Rahmat umat manusia menjadi bangsa yang besar dan berperadaban.(Hamka, 1990).

Adapun menurut Muhammad bin Abi Bakar ar-Razi dalam kitabnya Tafsir ar-Razi mengatakan bahwa rahmat Nabi Muhammad untuk masyarakat luas, barang siapa yang mengikuti ajaran-ajarannya akan selalu mendapat rahmatnya, tetapi kalau tidak mengikuti ajaran-ajarannya akan hilang rahmat dari jiwanya. Sifat rahmat yang lain adalah rahmat bagi seluruh golongan/ kelompok manusia yang memusuhinya. Nabi walaupun disakiti, dihina tetapi Nabi selalu mendoakan mereka. $^{2}$ (Ar-Razi, 1990).

\section{Surat Saba' (34): 28}

Ayat ini membicarakan kenabian Nabi Muhammad SAW, dengan mengatakan bahwa Allah Yang Maha Esa telah mengutus Nabi Muhammad dengan membawa bukti kebenaran yaitu Al-Qur'an.

Kata (kaffatan) menurut Thabathaba'i berarti menghalangi. Atas dasar itu beliau memahami penggalan ayat di atas bermakna: Kami tidak mengutusmu kecuali berfungsi sebagai penghalang yang sangat unggul terhadap manusia agar

${ }^{2}$ Doa yang sering dibaca ketika Nabi sakit, dihina musuhnya: Ya Allah berilah petunjuk kaumku karena mereka tidak mengetahui, Lebih lengkapnya lihat: Muhammad bin Abi Bakr ar-Razi, Tafsir Al-Razi. 
mereka tidak melakukan aneka kedurhakaan. Ini dikuatkan oleh kalimat sesudahnya yaitu basyiran wa nadziran. Beliau memahami kata "kaffah" dalam arti semua ayat ini menjelaskan keadaan seluruh manusia. Dengan demikian ayat ini menguraikan risalah Nabi Muhammad yang mencakup semua manusia. Ayat ini menurut mereka berarti Kami tidak mengutusmu kecuali pengutusan buat semua manusia. Pendapat ini sejalan dengan fungsi Nabi Muhammad yang diutus membawa rahmat bagi seluruh alam.

Ayat ini dipahami oleh Thabathaba'i mengandung argumentasi tentang Keesaan Allah SWT. Ulama ini menulis bahwa: "Risalah atau pengutusan para Nabi merupakan salah satu keniscayaan dan mengurus hamba-hamba-Nya serta mengantar mereka menuju kebahagiaan. Tetapi kebanyakan manusia tidak mengetahui dalam arti kebanyakan manusia tidak mengetahui bahwa keterbatasan sumber pengutusan rasul-rasul hanya Allah Yang Maha Esa.” (Shihab, 2004).

Sedangkan menurut Hamka ketika menafsirkan ayat ini: segala manusia yang mendiami permukaan bumi ini adalah tujuan misi pendidikan Nabi Muhammad dengan tidak memandang bangsa, tidak memandang batas daerah dan tidak memandang warna kulit, “menghibur dan mengancam”. Menghibur, memberikan kabar gembira tentang kebahagiaan jiwa di dunia ini keluar dari gelap gulita kebodohan menuju terang benderang iman yang nyata. Mengancam, berarti memberi peringatan barang siapa yang tidak mematuhi ajaran-Nya maka hidupnya akan gelap dan tidak terarah. (Hamka, 1982).

\section{Nilai-Nilai Pendidikan Surat Al-Anbiya' (21):107 dan Surat Saba'(34): 28}

\section{Pendidikan Tauhid}

Sebagai pendidik sekaligus Rasul, misi kependidikan pertama Muhammad SAW adalah menanamkan aqidah yang benar, yakni aqidah tauhid, mengesakan Tuhan, memahami seluruh fenomena alam dan kemanusiaan sebagai suatu kesatuan, suatu yang holistik. Melahirkan generasi yang cerdas secara intelektual, matang secara emosional dan kuat secara spiritual. (Jalaluddin, 2002). 


\section{Pendidikan yang Bernuansa Duniawi dan Ukhrowi}

Aspek tujuan pendidikan yang bernuansa duniawi dan ukhrawi inilah yang menjadi kajian menarik Michael H. Hart yang mengadakan penelitian pada tahun 1978 siapa di antara seratus tokoh yang berpengaruh di dalam sejarah, setelah diteliti ternyata tokoh yang berpengaruh di dunia ini bukan Karl Max, Thomas Alva Edison, Isaac Newton tetapi justru Nabi Muhammad SAW. (Hart, 1983).

Islam merupakan agama yang universal, yang memuat ajaran-ajaran yang berkaitan dengan segala aspek kehidupan manusia seperti ibadah, teologi, ajaran spiritual dan moral, tasawuf dan aspek-aspek lainnya. (Nasution, 1985).

Khusus aspek pendidikan yang menjadi bagian integral dari kehidupan manusia, juga mendapat perhatian dari para intelektual muslim. Ibnu Sina misalnya di samping berkiprah di bidang filsafat dan kedokteran juga mencurahkan perhatiannya di bidang pendidikan termasuk pendidikan bagi anakanak. (Al-Abrashi, tt).

Intensitas pengkajian bidang pendidikan yang bernuansa duniawi maupun ukhrawi, ternyata diteruskan oleh generasi-generasi muslim berikutnya. Muhammad Munir Mursi mengatakan bahwa bahasa tujuan esensial dari pendidikan Islam adalah mengantarkan manusia untuk mencapai kesempurnaan atau yang dikenal dengan insan kamil. Abdul Ghani Abud juga mengatakan bahwa pendidikan Islam merupakan sosok pendidikan yang menginterpretasikan antara pendidikan spiritual, pencerdasan akal dan pendidikan jasmani yang dapat dilaksanakan di berbagai tempat seperti, sekolah formal, Mesjid, tempat khalaqahkhalaqah dan lain-lainnya. (Abud, 1997).

\section{Peningkatan Kualitas}

Tidak ada keraguan lagi salah satu misi sentral Nabi Muhammad SAW adalah peningkatan kualitas SDM, yang benar-benar utuh, tidak hanya secara jasmaniyah tetapi juga secara batiniyah. Peningkatan kualitas SDM itu dilaksanakan dalam keselarasan dengan tujuan misi profetis Nabi, untuk mendidik manusia, memimpin mereka ke jalan Allah dan mengajar mereka untuk 
menegakkan masyarakat yang adil, sehat, harmonis, sejahtera secara material maupun spiritual. Nabi Muhammad diutus untuk mengembangkan kualitas kehidupan manusia, menyucikan moral mereka dan membekali mereka dengan bekal-bekal yang diperlukan untuk menghadapi kehidupan di dunia maupun di akhirat.

Setelah Nabi hijrah ke Madinah, Nabi Muhammad melaksanakan fungsi beliau sebagai pendidik utama dalam pembangunan masyarakat, sosial politik, masyarakat politik keagamaan Islam di Madinah. Di Madinah, Nabi tidak hanya menciptakan tatanan politik, sebagaimana direfleksikan dalam "Konstitusi Madinah", tetapi juga membangun tradisi pendidikan Islam yaitu fungsional masjid, misalnya tidak hanya sebagai tempat melakukan shalat, tetapi juga melakukan pendidikan dalam pengertian seluas-luasnya. (Azra, 2002).

Bahwa pendidikan dalam pengertian khusus dan terbatas, merupakan salah satu aspek terpenting dari membebaskan para tawanan kafir Quraisy setelah mereka mengajar anak-anak muslim untuk membaca-menulis. Melalui kebijaksanaan seperti ini Nabi Muhammad memberikan teladan, bahwa segala potensi yang ada di lingkungan kaum muslimin, sekalipun potensi itu ada dipunyai non muslimin, dapat didayagunakan untuk peningkatan kualitas SDM muslim.

\section{Pendidikan Akhlak dan Suri Tauladan (Uswah Hasanah)}

Akhlak adalah kebiasaan seseorang atau masyarakat dalam bentuk ucapan maupun perbuatan yang sudah membudaya dan mendarah daging dalam kehidupan sehari-hari. Seseorang yang mengaku kasihan terhadap yatim piatu baru bertaraf pernyataan atau perasaan yang abstrak (rahmat) yang masih perlu dimanifestasikan dengan akhlak menyantuni atau menolong si yatim. Al Islamu dinul 'amal. Islam adalah agama karya. Addin almu'amalah, Agama adalah interaksi antar manusia.

Kedua hadits itu mempertegas, Islam sebagai ajaran bukan sebatas teori atau pemikiran belaka, tapi akhir dan dinamis dalam kehidupan konkrit. 
Kata para sejarawan: History is but the life of great man, sejarah hanyalah catatan kehidupan orang besar. Jika kita sepakat dengan pernyataan itu, maka tak ada manusia yang catatan sejarahnya harum dan lebih mengagumkan dari Nabi Muhammad SAW. Tak mengherankan kalau banyak sekali sejarawan dan ilmuwan yang tertarik menulis tentang Rasulullah SAW, baik muslim maupun non muslim.

Michael Heart, ilmuwan Amerika yang beragama Nasrani dalam buku terkenalnya yang diterjemahkan dengan judul Seratus Tokoh menyatakan, The Topmost of 100 is Muhammad, dari yang pernah ada di dunia, Nabi Muhammad SAW dinilai sebagai terbesar pengaruhnya dan paling sukses sebagai pemimpin.

Prof. William Muir (Inggris) dalam bukunya: The Life of Muhammad juga mengatakan: Kapanpun dan bagaimanapun kita mempelajari perilaku kehidupan Muhammad SAW, senantiasa akan menemukan keutamaan yang terpadu dengan keluhuran cita dan kemuliaan akhlak yang tiada bandingannya sepanjang masa.

Para ulama Islam sendiri banyak yang merasa tak mampu berbicara banyak tentang akhlak Qur'ani Rasulullah SAW. Dr. Ahmat Muhammad Alhufi (Mesir) dalam bukunya Min Akhlaqin Nabi mengungkapkan, keterbatasan tangannya untuk menulis tentang Rasulullah SAW. dalam mukadimah ia mengisahkan tatkala berziarah ke makam Rasul di Madinah. Ia merasa perlu "meminta izin" terlebih dahulu dan dalam kesendiriannya di Raudhoh ia berdoa penuh khusyuk dan tawadhuk: Wahai Rasul Allah dapatkah kiranya tangan pendek dan pena yang tumpul ini menulis tentang kebesaranmu. Dapatkah sebutir pasir akan berbicara tentang sahara yang amat luas. Mungkinkah setetes air yang mengungkap samudera yang sangat besar. Seberkas sinar mustahil akan tertutur tentang matahari. Apa yang mampu saya tuliskan dalam buku sederhana ini hanyalah percikan kecil dari keluhuran akhlakmu dan ketinggian harkat dan martabat dirimu.

Ulama Pakistan, Abul 'Ala Al-Maududi dalam bukunya The Prophet of Islam mengatakan, He is the only example all excellences have been blended into one personality, dialah satu-satunya pribadi yang di dalamnya terkumpul segala 
keistimewaan. Pantas kiranya kalau Dr. A.M. Alhufi mengaku sulit mencari pilihan untuk menulis tentang akhlak Rasulullah SAW. Kata beliau: Saya merasa seakan berada di kebun yang amat memukau. Setiap melihat bunga yang indah dan buah yang menggiurkan mengira itu yang terbaik, ternyata yang lain pun memberi kesan yang sama. Akhirnya tiada yang dapat disimpulkan kecuali mengatakan semuanya terbaik dan terindah.

Semua yang ada pada diri Rasulullah SAW baik sikap, ucapan, pemikiran maupun perbuatannya (menurut Allah) adalah uswatun hasanah, contoh yang terbaik, (QS.32:21). Betapa damai dan penuh rahmat dunia ini sekiranya para "petingginya" banyak yang memanfaatkan tuntunan Nabi Muhammad SAW.

Abul Hasan Annadawi (ulama India) mengatakan dalam sebuah tulisannya, kalau saja dunia benar-benar memanfaatkan Al-Qur'an, dunia yang kita lihat tak seperti sekarang ini. Tak akan ada saling bermusuhan. Perintah Allah yang diajarkan oleh Nabi Muhammad SAW: tolong menolong atas dasar kebajikan dan takwa, bukan berdasarkan dosa dan permusuhan. (QS.:5:2).

Nabi Muhammad SAW memang manusia sempurna (insan kamil) yang dipersiapkan oleh Allah SWT untuk menjadi teladan bagi umat manusia dalam semua aspek kehidupan. Semakin banyak kita mengenal perilaku kehidupan beliau, diharapkan semakin banyak yang dapat diteladani.

Betapa kehidupan saat ini semakin perlu sentuhan ajaran beliau. Sadisme, tindakan kriminal, ketidakadilan hampir setiap hari diberitakan oleh media massa. Kebidaban dan penindasan seperti yang terjadi di Palestina, kelaparan di Afrika dan masih banyak lagi contoh yang lain, adalah dari perbuatan manusia yang hatinya gersang dari rahmat dan amat memerlukan akhlak yang diajarkan oleh Rasulullah SAW. Beliau bukan saja mewajibkan kita berakhlak luhur terhadap Allah SWT dan sesama manusia, tapi juga terhadap hewan dan benda tak bernyawa sekalipun kita harus santun, tak mencampakkan atau menyia-nyiakan.

Salah satu kebiasaan Rasulullah adalah memberi nama kepada bendabenda yang digunakan setiap hari. Misalnya pedang beliau bernama: Dzul Fiqor 
cerminnya disebut: Midallah setiap kali memerlukan atau mencari barang-barang itu beliau memanggil namanya bukan jenis bendanya. Beliau "memanusiakan" dan menghargai jasa benda itu dalam bentuk pemeliharaan dan kasih sayang. Perilaku yang sangat kontras jika dibandingkan dengan perlakuan kapitalis yang tak memanusiakan pegawainya.

Dalam kehidupan berkeluarga dan bermasyarakat Rasulullah SAW tak pernah sama sekali memukul seseorang atau seekor hewan pun. Tatkala ada wanita berlaku sadis terhadap kucing, Rasulullah SAW mengatakan, wanita itu masuk neraka, karena hewan tak berdosa itu dipenjarakan dalam kamar sampai mati kelaparan.

Ada pula seorang ibu yang banyak beribadah (santri) tapi berakhlak jelek terhadap tetangganya. Kata Nabi Muhammad SAW ibu itu tak masuk surga. Sebaliknya orang yang dikenal hidup berlumur dosa mendapat rahmat Allah hanya karena menolong seekor anjing yang kehausan di padang pasir. Ia memberi air yang didapatkannya dengan susah payah dan ikhlas. Kata Nabi Muhammad SAW, orang itu masuk surga karena seekor anjing.

Kisah-kisah itu dapat ditemukan dalam hadits. Namun hendaknya tak diinterpretasikan betapa mudah masuk surga atau terjerumus dalam neraka, melainkan harus dibaca dengan falsafah rahmatan lil 'alamin. Di dalam peristiwa itu terkandung nasehat agar kita tak menyepelekan perbuatan baik sekecil apapun, sebab bisa jadi perbuatan kecil yang ikhlas mengundang rahmat Allah. Demikian pula dosa agar tak dikucilkan. Sebab bisa jadi perilaku yang tumbuh dari kesadisan hati meski terhadap kucing mengundang murka Allah SWT, apalagi terhadap manusia.

Rasulullah SAW pernah membuatkan pernyataan yang mengejutkan para sahabat. Kata beliau: Manusia tak masuk surga karena amalnya? apakah itu juga berlaku bagi diramu ya Rasulullah? Nabi menjawab: Ya! Manusia masuk surga karena rahmat Allah SWT. Artinya tak ada seorang sadis masuk surga. Kata Rasulullah: Manusia yang tak berbelas kasih tak dirahmati oleh Allah. (Taufiq, 1994). 


\section{Kesimpulan}

1. Surat Al-Anbiya': 107 Allah menjelaskan bahwa Nabi Muhammad kesemuanya mengisyaratkan sifat-sifat rahmat bagi seluruh alam tidak terbatas pada manusia, waktu dan tempat. Barang siapa yang mengikuti ajaranajarannya akan selalu mendapat rahmatnya, kalau tidak mengikuti ajaranajarannya akan hilang rahmat dari jiwanya.

2. Surat Saba': 28 Allah menjelaskan kenabian Nabi Muhammad, dengan menyatakan bahwa Allah Yang Maha Esa telah mengutus Nabi Muhammad dengan membawa bukti kebenaran yaitu Risalah Nabi Muhammad tidak terfokus pada orang-orang Arab Badui saja tetapi meliputi seluruh manusia, tidak memandang bangsa, batas daerah dan warna kulit.

3. Nilai-nilai pendidikan yang terdapat pada kedua ayat di atas adalah penanaman pendidikan tauhid sejak dini, pendidikan yang berorientasi pada duniawi dan ukhrawi peningkatan kualitas SDM muslim serta pendidikan akhlaq dan uswatun hasanah (suri tauladan)

4. Rasulullah memanifestasikan ajaran rahmatan lil alamin dengan cara berbelas kasih terhadap semua manusia tidak pandang suku, agama, ras dan golongan.

\section{Penutup}

Demikian pokok-pokok kajian surat Surat Al-Anbiya': 107, Saba': 28. Penulis menyadari bahwa tulisan ini masih jauh dari nilai kesempurnaan. Akhirnya merupakan kebahagiaan tersendiri bagi penulis apabila berkenaan memandang tulisan ini dari nilai manfaatnya. 


\section{Daftar Pustaka}

Abdul Ghani Abud, Fi Al-Tarbiyah Al-Islamiyah Mesir: Dar Al-Fikri, Beirut, 1997

Al-Abrashi, Muhammad Athiyah, Tarbiyah Al Islamiyah Wa Falsafatuna, (Beirut: Dar Al-Fikr Beirut, tt:

Ar-Razi, Muhammad bin Abi Bakr, Tafsir Al-Razi, Beirut, Lebanon: Dar Al-Fikr, 1990

Azra, Azmardi, Pendidikan Islam Tradisi dan Modernisasi Menuju Milenium Baru, Jakarta: Logos, 2002

Hamka, Tafsir Al-Azhar, Jakarta: Panjimas, Juz 22, 1982

Hamka, Tafsir Al-Azhar, Jakarta: Panjimas, Juz 17, 1990

Hart, Michael H., Seratus Tokoh yang Berpengaruh di Dunia. Terj. Jakarta: Panjimas, 1983

Jalaluddin, Teologi Pendidikan, Jakarta: Grafindo Persada, 2002

Nasution, Harun, Islam Ditinjau dari Berbagai Aspeknya Jakarta: UI Press, 1985

Shihab, M. Quraish, Tafsir Al-Misbah Jakarta: Lentera Hati, Vol. 8, 2004

Shihab, M. Quraish, Tafsir Al-Misbah Jakarta: Lentera Hati, Vol. II, 2004

Tarjamah al-Fadl Al-Qur'an Jakarta: Al-Hikmah, Jilid VIII, 1993

Tarjamah al-Fadl Al-Qur'an Jakarta: Al-Hikmah, Jilid VI, 1993

Taufiq, Muhammad, Kehidupan Rasulullah Manifestasi Rahmatan Lil Alamin,

Surabaya Pos, 1994 